\title{
THEORETICAL AND EXPERIMENTAL STUDIES ON VIBRATIONS PRODUCED BY DEFECTS IN DOUBLE ROW BALL BEARING USING RESPONSE SURFACE METHOD
}

\author{
Shinde Ashaykumar A ${ }^{\mathbf{1}}$, Desavale Ramchandra $\mathbf{G}^{\mathbf{2}}$, Kumbhar Surajkumar $\mathbf{G}^{\mathbf{3}}$ \\ ${ }^{I}$ P.G. Student, Department of Mechanical Engineering, A.D.C.E.T, Ashta, Maharashtra, India \\ ${ }^{2}$ Associate Professor, Department of Mechanical Engineering, A.D.C.E.T, Ashta, Maharashtra, India \\ ${ }^{3}$ P.G. Student, Department of Mechanical Engineering, A.D.C.E.T, Ashta, Maharashtra, India
}

\begin{abstract}
Rolling element bearings are widely used as low friction joints between rotating machine components. In industrial applications, bearings are considered as critical mechanical components and a defect in such a bearing, unless detected in time, causes malfunction and may even lead to catastrophic failure of the machinery. The research work presented focuses upon the detection of a localized defect in a double row ball bearing using vibration analysis. For bearing analysis, frequency domain approach is taken followed by experimentation for the detection of vibration signal in which single point defects are artificially created on ball, inner race and outer race, then for vibration response these defected double row ball bearings are tested under different speed and loading conditions, and resulting vibration signals are then processed using considered vibration-based techniques in frequency domain. DOE method like Response Surface Method (RSM) is used as a medium for fault detection. These results are given by graphs with like contour plot and surface plot.
\end{abstract}

Keywords- Double row ball Bearing, Vibration, Bearing Fault, Vibration Analysis, Fault Diagnosis, Response Surface Method etc.

\section{INTRODUCTION}

Rolling element bearings are used in a wide variety of rotating machines from small hand-held devices to heavy duty industrial systems and are primary cause of breakdowns in these machines. In the rotating machines, one of the major concerns is fatigue failure in rolling element bearing components. When the repeatedly cycled stress on a surface in rolling contact it exceeds the endurance strength of the material, fatigue cracking of the surface occurs. This defect propagates and a result in a large pits or spalls on the surface of bearing components. A small fault in the bearing systems can quickly develop into a dangerous failure mode without any notable signs. Therefore, accurate machinery fault diagnosis is becoming of paramount importance to avoid catastrophic failure and human casualties.

The several vibration and acoustic measurement methods have been used for the detection of defects and to monitor the condition of bearing. Vibration signals are analyzed using frequency domain analysis. Vibration signal is measured from the FFT signal processing techniques, are employed to extract the fault sensitive features to serve as the monitoring indices [4]. Theoretical predictions based on experimental observations mark the essence of useful research. Proper use of statistical methods greatly improves the efficiency of the experiments and helps to draw meaningful conclusions from the experimental data. Design of experiments (DOE) helps to understand how the influence factors interact with the system. Methods such as factorial design, Response Surface Method (RSM) [3].

Jose Mathew et al. [2] presented an analytical model for predicting the effect of a localized defect on the ball bearing vibrations. The contact force was calculated using the Hertzian contact deformation theory. Patil M.S. et al. [3] studied that the presence of defect in the bearing results in increased vibrations. Time domain indices such as rms, crest factor, and kurtosis were some of the important parameters used to monitor the condition of the bearing with RSM he has developed the model with Kurtosis. Choudhury et al. [5] proposed rotor-bearing system model which predicts significant components at the harmonics of characteristic defect frequency for a defect on the particular bearing element. Gallina et al. [6] explained response surface method (RSM) is utilized to analyze the effects of design and operating parameters on the vibration signature of a Rotor bearing system. Distributed defects are considered such as internal radial clearance and surface waviness of the bearing components.

From the review of the relevant literature on vibration detection and analysis in rolling element bearings, it is noticed that no effort has been made on applying RSM for double row ball bearings. The present study, identify the effects of localized defect on amplitude of vibration using Response surface method (RSM) with the combination effects of these defects on the double row ball bearings. This 
work attempts to analyze vibration responses of a rotorbearing system supported on double row ball bearings.

\section{FREQUENCY-DOMAIN APPROACH}

As the bearing rotates, these impulses will occur periodically with a frequency which is dependent on the location of the defect. Equations are available which enable the frequency to be calculated from knowledge of the bearing geometry and the shaft speed. A model presented predicted frequency spectrum having peaks at these frequencies. Defects in components of rolling element bearing such as inner race, outer race, rolling elements and cage generate a specific defect frequencies calculated theoretically from the below equations $[1,7]$

FTF - Fundamental Train Frequency:

$\mathrm{FTF}=\frac{1}{2} S\left(1-\frac{B_{d}}{P_{d}} \cos \theta\right) \frac{\mathrm{rpm}}{60}$

BPFI - Ball Pass Frequency of the Inner race:

$\operatorname{BPFI}\left(f_{i}\right)=\frac{Z}{2} S\left(1+\frac{B_{d}}{P_{d}} \cos \theta\right) \frac{r p m}{60}$

BPFO - Ball Pass Frequency of Outer race:

$\operatorname{BPFO}\left(f_{0}\right)=\frac{Z}{2} S\left(1-\frac{B_{d}}{P_{d}} \cos \theta\right) \frac{r p m}{60}$

BSF - Ball Spin Frequency:

$\operatorname{BSF}\left(f_{r}\right)=\frac{P_{b}}{2 B_{d}} S\left(1-\left(\frac{B_{d}}{P_{d}}\right)^{2}(\cos \theta)^{2}\right) \frac{r p m}{60}$

Rolling Element Defect Frequency or 2 x BSF

$R D F=\frac{P_{b}}{B_{d}} S\left(1-\left(\frac{B_{d}}{P_{d}}\right)^{2}(\cos \theta)^{2}\right) \frac{r p m}{60}$

Where,

$\mathrm{S}=$ Rotational speed of the shaft in rpm

$\mathrm{Z}=$ No of rolling elements

$\mathrm{B}_{\mathrm{d}}=$ Roller diameter in $\mathrm{mm}$

$\mathrm{P}_{\mathrm{d}}=$ Bearing pitch diameter

$\theta=$ Contact angle

The assumption made that there is no sliding and only pure rolling contact between the rolling elements and the races but in reality, there exist some sliding. Table 2 shows Different frequencies for outer race, inner race and rolling element/ball are calculated by considering different speed conditions.

\section{EXPERIMENTAL STUDY}

In the following, the vibration signals of tapered roller bearings (SKF 1208ET9) are studied. The electricaldischarge machining method is applied to produce artificial defects on the surface of bearing components which are roller and outer race. The defect sizes and shapes are described in Table 1 and the description of the test rig is shown in Fig. 1. The vibration signals are measured on the housing of the test bearing by mounting an accelerometer has sensitivity $105.5 \mathrm{mV} / \mathrm{g}$.

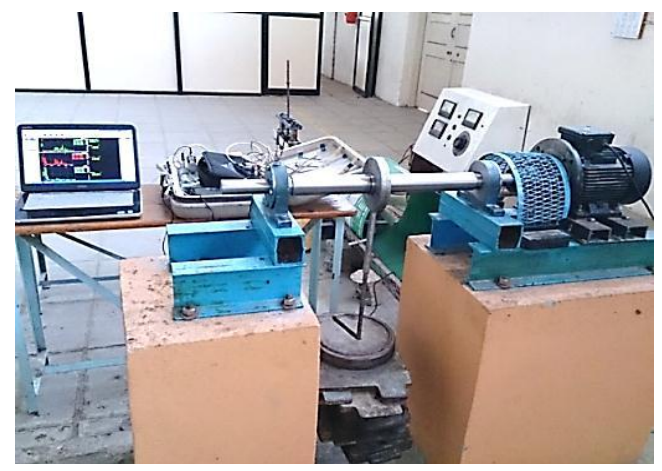

Fig. 1 Schematic of the test rig

The measured direction is radial to the shaft. The tested bearings run at 800 and $1400 \mathrm{rev} / \mathrm{min}$. The sampling rate of vibration signal is $25 \mathrm{kHz}$. According to the spectra of bearing vibrations, the frequency band from 3 to $5 \mathrm{kHz}$ is chosen. According to the dimension of tested bearings, the characteristic frequencies for roller defect, outer- and inner race defect are shown in Table 2.

Table 1 Defect in bearings

\begin{tabular}{|c|c|c|c|c|}
\hline \multirow[b]{2}{*}{$\begin{array}{l}\text { Sr. } \\
\text { No. }\end{array}$} & \multirow[b]{2}{*}{$\begin{array}{l}\text { Defect } \\
\text { type }\end{array}$} & \multirow[b]{2}{*}{$\begin{array}{l}\text { Single/Double } \\
\text { side }\end{array}$} & \multicolumn{2}{|c|}{ Defect size } \\
\hline & & & $\begin{array}{l}\text { Radius } \\
\text { in } \mathbf{~ m m}\end{array}$ & $\begin{array}{l}\text { Depth } \\
\text { in } \mathbf{~ m m}\end{array}$ \\
\hline \multirow{5}{*}{1.} & \multirow{5}{*}{$\begin{array}{l}\text { Inner } \\
\text { race } \\
\text { defect }\end{array}$} & \multirow{3}{*}{ Single } & 0.5 & 0.5 \\
\hline & & & 1 & 1 \\
\hline & & & 2 & 2 \\
\hline & & \multirow{2}{*}{ Double } & 1 & 1 \\
\hline & & & 2 & 2 \\
\hline \multirow{3}{*}{2.} & \multirow{3}{*}{$\begin{array}{l}\text { Ball } \\
\text { defect }\end{array}$} & \multirow{3}{*}{ Single } & 0.5 & 0.5 \\
\hline & & & 1 & 1 \\
\hline & & & 2 & 2 \\
\hline \multirow{5}{*}{3.} & \multirow{5}{*}{$\begin{array}{l}\text { Outer- } \\
\text { race } \\
\text { defect }\end{array}$} & \multirow{3}{*}{ Single } & 0.5 & 0.5 \\
\hline & & & 1 & 1 \\
\hline & & & 2 & 2 \\
\hline & & \multirow{2}{*}{ Double } & 1 & 1 \\
\hline & & & 2 & 2 \\
\hline
\end{tabular}

Table 2 Characteristic frequencies for the bearing

\begin{tabular}{|l|l|l|l|}
\hline \multirow{2}{*}{$\begin{array}{l}\text { Speed }(\boldsymbol{N}) \\
\text { rpm }\end{array}$} & \multicolumn{4}{|l|}{ Defect frequency, $\boldsymbol{H z}$} \\
\cline { 2 - 4 } & Outer-race $\left(\boldsymbol{f}_{\boldsymbol{o}}\right)$ & Ball $\left(\boldsymbol{f}_{\boldsymbol{r}}\right)$ & Inner-race $\left(\boldsymbol{f}_{\boldsymbol{i}}\right)$ \\
\hline 800 & 97.008 & 90.672 & 129.648 \\
\hline 1100 & 133.386 & 124.674 & 178.266 \\
\hline 1400 & 169.764 & 158.676 & 226.884 \\
\hline
\end{tabular}

\section{RESPONSE SURFACE METHOD (RSM)}

Response surface methodology is a collection of mathematical and statistical techniques that are useful for modeling and analysis of problems in which a response of interest is influenced by several variables. 
The RSM designs are classified into central composite design and Box Behnken design. The present work uses Box and Behnken [8] introduced designs for three level factors that are widely used in response surface methods to fit second-order models to the response. The designs were developed by the combination of two level factorial designs with incomplete block designs. The design is obtained by the combination of 22 designs with a balanced incomplete block design having three treatments and three blocks. The advantages of these designs include the fact that they are all spherical designs and require factors to be run at only three levels and there are no runs where all factors are at either the +1 (highest value) or -1 (lowest value) levels [3].The design matrix designed for experimentation with the help of MINITAB software with Box-Behnken designs and considering three factors. The factors are Defect size (Circular in mm), Load (in N) and Speed (in rpm). Factor and their level are given in Table 3 design matrix and their respective values are as given in Table 4.

Table 3 Factor and their level

\begin{tabular}{|l|l|l|l|l|}
\hline \multirow{2}{*}{ Factor } & \multirow{2}{*}{ Notation } & \multicolumn{3}{|c|}{ Values or Levels coded } \\
\cline { 3 - 5 } & & -1 & 0 & +1 \\
\hline Defect size $(\mathrm{mm})$ & $\mathrm{D}$ & 0.5 & 1 & 2 \\
\hline $\operatorname{Load}(\mathrm{N})$ & $\mathrm{W}$ & 500 & 1000 & 1500 \\
\hline Speed $(\mathrm{rpm})$ & $\mathrm{N}$ & 800 & 1100 & 1400 \\
\hline
\end{tabular}

Table 4 Design Matrix

\begin{tabular}{|c|c|c|c|c|c|c|}
\hline \multirow{2}{*}{$\begin{array}{l}\text { Sr. } \\
\text { No }\end{array}$} & \multirow{2}{*}{$\begin{array}{l}\text { Defec } \\
\mathbf{t} \\
\text { size }( \\
\mathrm{mm})\end{array}$} & \multirow{2}{*}{$\begin{array}{l}\text { Loa } \\
\text { d } \\
(N)\end{array}$} & \multirow{2}{*}{$\begin{array}{l}\text { Spee } \\
\text { d } \\
(\mathbf{r p m})\end{array}$} & \multicolumn{3}{|c|}{ Amplitudes $\left(\mathrm{mm} / \mathrm{s}^{2}\right)$} \\
\hline & & & & Ball & Outer & Inner \\
\hline 1. & 1 & 500 & 1400 & 0.0371 & 0.0122 & $\begin{array}{l}0.0127 \\
1\end{array}$ \\
\hline 2. & 2 & 1000 & 1400 & 0.0329 & 0.0112 & 0.0285 \\
\hline 3. & 0.5 & 1000 & 1400 & 0.0269 & $\begin{array}{l}0.0060 \\
1\end{array}$ & $\begin{array}{l}0.0041 \\
1\end{array}$ \\
\hline 4. & 1 & 1500 & 1400 & 0.0174 & $\begin{array}{l}0.0088 \\
1\end{array}$ & $\begin{array}{l}0.0093 \\
2\end{array}$ \\
\hline 5. & 2 & 1000 & 800 & 0.0222 & $\begin{array}{l}0.0099 \\
2\end{array}$ & 0.0165 \\
\hline 6 & 2 & 1500 & 1100 & 0.0189 & $\begin{array}{l}0.0080 \\
1\end{array}$ & 0.0141 \\
\hline 7. & 1 & 1000 & 1100 & $\begin{array}{l}0.0097 \\
4\end{array}$ & $\begin{array}{l}0.0073 \\
3\end{array}$ & $\begin{array}{l}0.0094 \\
2\end{array}$ \\
\hline 8. & 1 & 1000 & 1100 & $\begin{array}{l}0.0097 \\
4\end{array}$ & $\begin{array}{l}0.0073 \\
3\end{array}$ & $\begin{array}{l}0.0094 \\
2\end{array}$ \\
\hline 9. & 0.5 & 1000 & 800 & $\begin{array}{l}0.0040 \\
7\end{array}$ & $\begin{array}{l}0.0067 \\
1\end{array}$ & $\begin{array}{l}0.0032 \\
3\end{array}$ \\
\hline 10. & 0.5 & 1500 & 1100 & $\begin{array}{l}0.0044 \\
1\end{array}$ & $\begin{array}{l}0.0070 \\
8\end{array}$ & $\begin{array}{l}0.0031 \\
9\end{array}$ \\
\hline 11. & 1 & 1500 & 800 & $\begin{array}{l}0.0047 \\
8 \\
\end{array}$ & $\begin{array}{l}0.0030 \\
3\end{array}$ & $\begin{array}{l}0.0081 \\
2\end{array}$ \\
\hline 12. & 1 & 500 & 800 & $\begin{array}{l}0.0091 \\
7 \\
\end{array}$ & $\begin{array}{l}0.0063 \\
6\end{array}$ & $\begin{array}{l}0.0127 \\
5\end{array}$ \\
\hline 13. & 0.5 & 500 & 1100 & $\begin{array}{l}0.0093 \\
9\end{array}$ & $\begin{array}{l}0.0090 \\
2\end{array}$ & $\begin{array}{l}0.0043 \\
6\end{array}$ \\
\hline 14. & 2 & 500 & 1100 & 0.0438 & $\begin{array}{l}0.0081 \\
8 \\
\end{array}$ & 0.0305 \\
\hline
\end{tabular}

\begin{tabular}{|l|l|l|l|l|l|l|}
\hline 15. & 1 & 1000 & 1100 & $\begin{array}{l}0.0097 \\
4\end{array}$ & $\begin{array}{l}0.0073 \\
3\end{array}$ & $\begin{array}{l}0.0094 \\
2\end{array}$ \\
\hline
\end{tabular}

Then MINITAB software package is used to find out the following effects of above results with various graphs and statistical analysis. We have considered various things like main effects plot, contour plot of two types and surface plot of two types. These are as follows for outer race defect, inner race defect and ball defect.

\section{RESULTS AND DISCUSSION}

\subsection{RSM for Outer Race Defect}

For outer race defect from the values as given in Table 4 we have got following results and plots.

Table 5 Analysis of Variance for Outer

\begin{tabular}{|l|l|l|l|l|l|}
\hline Source & DF & Seq. SS & MS & $\begin{array}{l}\text { F- } \\
\text { value }\end{array}$ & $\begin{array}{l}\text { P- } \\
\text { value }\end{array}$ \\
\hline $\mathrm{D}$ & 2 & 0.0001097 & 0.0000549 & 65.74 & 0.038 \\
\hline $\mathrm{W}$ & 2 & 0.0000099 & 0.0000050 & 5.94 & 0.026 \\
\hline $\mathrm{N}$ & 2 & 0.0000002 & 0.0000001 & 0.13 & 0.068 \\
\hline Error & 8 & 0.0000067 & 0.0000008 & & \\
\hline Total & 14 & 0.0001266 & & & \\
\hline $\begin{array}{l}\text { S }=0.000913530 \quad \mathrm{R}-\mathrm{Sq}=94.73 \% \\
\text { 93.77\% }\end{array}$ \\
\hline
\end{tabular}

Table 5 shows the results of ANOVA for outer race defect. The $R^{2}$ and $R^{2}$-(adj) for the outer race are 0.9473 and 0.9377 respectively. This indicates that the variables (predictors) excellently explain the amount of variation in the observed value of the amplitudes. The $\mathrm{P}$ values are nearly equal to zero in the analysis table shown above. The main effect plot (figure 2), contour plots and surface plots (figure 3 and 4) are as shown below.

Figure 2 shows main effect plot, where amplitudes are increasing with defect size and speed but decreases with increasing load. Also for outer race defect it shows nearly linear plot. Also for contour plot, at the highest load and lowest defect size values of amplitudes are very less but at lowest load and highest defect size amplitudes are high. Also it shows linear variation in the first graph. These same effects are seen in the surface plot graph of load and defect size as well as speed and defect size [3,9] which gives exactly same effect given by experimental result.

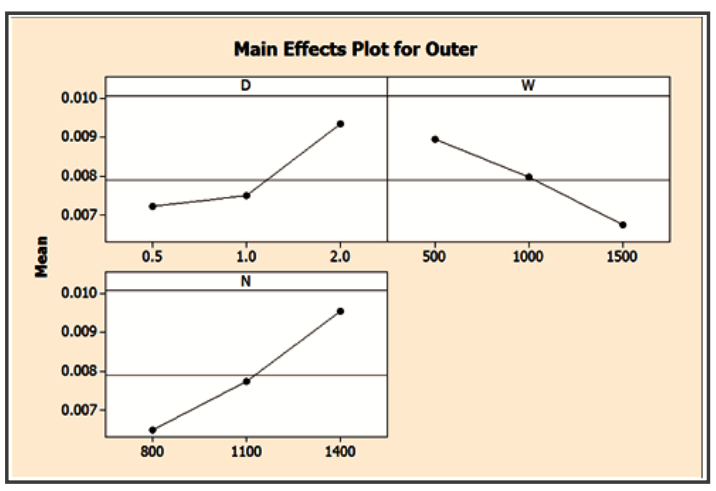

Fig 2 Main Effects plot for outer race defect 


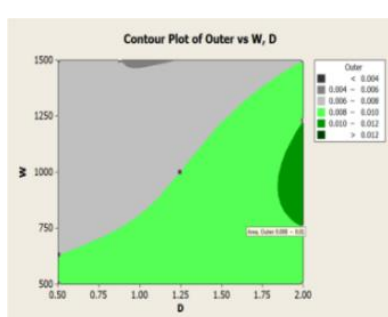

(a)

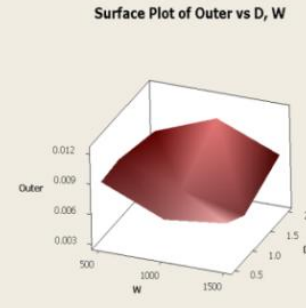

(b)
Fig 3 Contour plot and surface plot for outer race defect considering load and defect size

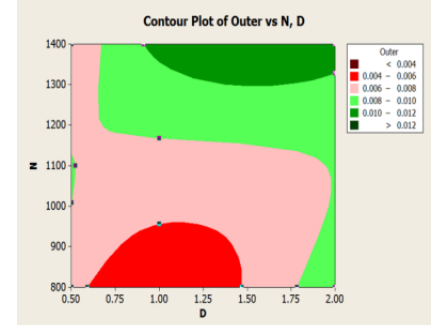

(a) (b)

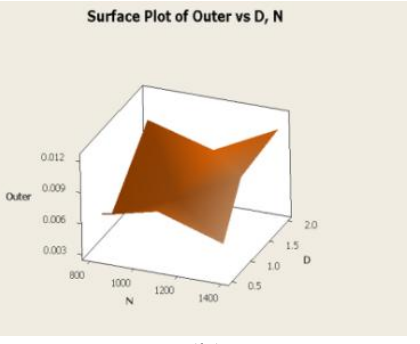

Fig 4 Contour plot and surface plot for outer race defect considering Speed and defect size

\subsection{RSM for Defect on Ball/Roller:}

For defect on ball from the values as given in Table 4 we have got following results and plots.

Table 6 Analysis of Variance for Ball

\begin{tabular}{|l|l|l|l|l|l|}
\hline Source & DF & Seq. SS & MS & $\begin{array}{l}\text { F- } \\
\text { value }\end{array}$ & $\begin{array}{l}\text { P- } \\
\text { value }\end{array}$ \\
\hline $\mathrm{D}$ & 2 & 0.0018185 & 0.0009062 & 166.23 & 0.046 \\
\hline $\mathrm{W}$ & 2 & 0.0002424 & 0.0001215 & 22.28 & 0.051 \\
\hline $\mathrm{N}$ & 2 & 0.0000185 & 0.0000092 & 1.70 & 0.049 \\
\hline Error & 8 & 0.0000436 & 0.0000055 & & \\
\hline Total & 14 & 0.0021230 & & & \\
\hline $\mathrm{S}=0.00233489$ & $\mathrm{R}-\mathrm{Sq}=97.95 \% \quad \mathrm{R}-\mathrm{Sq}(\mathrm{adj})=96.40 \%$ \\
\hline
\end{tabular}

Table 6 shows the results of ANOVA for ball/roller defect. The $\mathrm{R}^{2}$ and $\mathrm{R}^{2}$-(adj) for the ball/roller are 0.9795 and 0.9640 respectively. This indicates that the variables (predictors) excellently explain the amount of variation in the observed value of the amplitudes. The $\mathrm{P}$ values are nearly equal to zero in the analysis table shown above or these values are less than 0.05 so these are considerable value. The main effect plot (figure 5), contour plots and surface plots (figure 6 and 7) are as shown below.

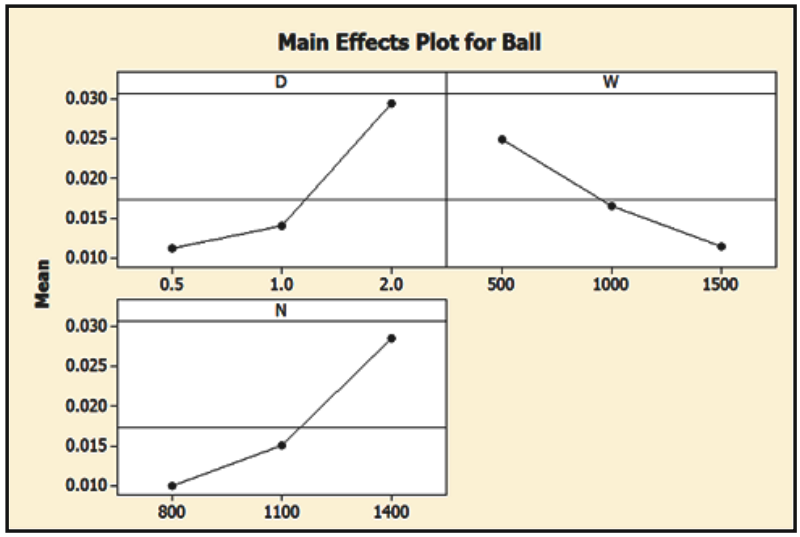

Fig 5 Main Effects plot for defect on ball

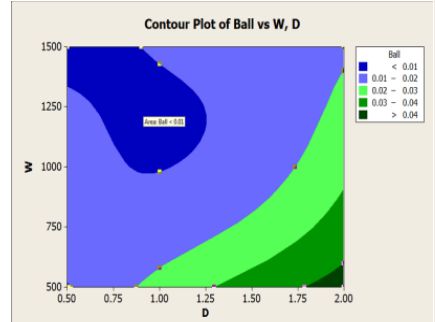

(a)

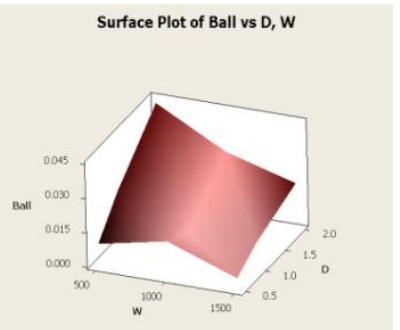

(b)
Fig 6 Contour plot and surface plot for defect on ball considering load and defect size

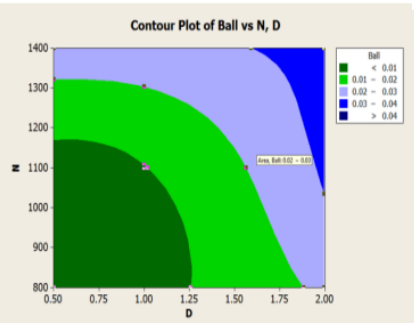

(a)

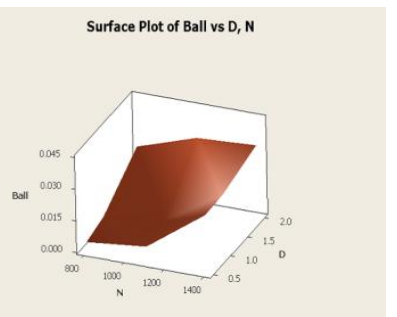

(b)
Fig 7 Contour plot and surface plot for defect on ball considering speed and defect size

The Figure 5 main effect plot is show that amplitudes are increasing with defect size and speed but decreases with increasing load. For defect on ball it shows nearly linear plot for load variation but for defect size it will shows abrupt changes. Also from contour plot it has been observed that at the highest load and lowest defect size values of amplitudes are very less but at lowest load and highest defect size amplitudes are high it will concentrated in the lower right corner. But for speed and defect size contour plot (Figure 6 and Figure 7) it will give much of area under the graph. These indicate exactly same effect given by experimental result $[3,9]$.

\subsection{RSM for Inner Race Defect}

For inner race defect from the values as given in Table 4, we have got following results and plots. 
Table 7 Analysis of Variance for Inner

\begin{tabular}{|l|l|l|l|l|l|}
\hline Source & DF & Seq. SS & MS & $\begin{array}{l}\text { F- } \\
\text { value }\end{array}$ & $\begin{array}{l}\text { P- } \\
\text { value }\end{array}$ \\
\hline $\mathrm{D}$ & 2 & 0.0007290 & 0.0003653 & 24.79 & 0.057 \\
\hline $\mathrm{W}$ & 2 & 0.0000831 & 0.0000417 & 2.83 & 0.048 \\
\hline $\mathrm{N}$ & 2 & 0.0000263 & 0.0000132 & 0.89 & 0.047 \\
\hline Error & 8 & 0.0001179 & 0.0000147 & & \\
\hline Total & 14 & 0.0009563 & \multicolumn{1}{|c|}{} & \\
\hline $\mathrm{S}=0.00383899$ & $\mathrm{R}-\mathrm{Sq}=97.67 \%$ R-Sq(adj) $=98.42 \%$ \\
\hline
\end{tabular}

Table 7 shows the results of ANOVA for inner race defect. The $R^{2}$ and $R^{2}$-(adj) for the inner race are 0.9767 and 0.9842 respectively. This indicates that the variables (predictors) excellently explain the amount of variation in the observed value of the amplitudes. The $\mathrm{P}$ values are nearly equal to zero in the analysis table shown above. The main effect plot (figure 8), contour plots and surface plots (figure 9 and 10) are as shown below.

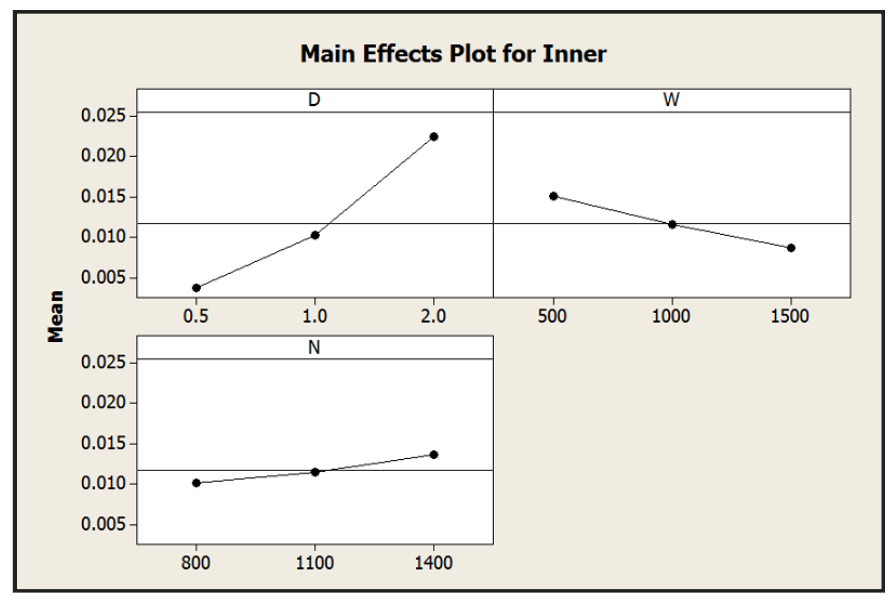

Fig 8 Main Effects plot for defect on inner race
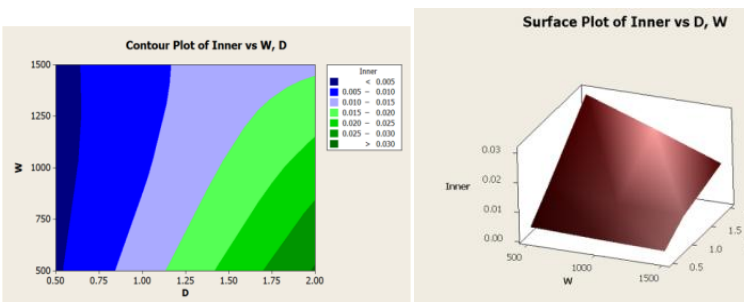

Fig 9 Contour plot and surface plot for defect on inner race considering load and defect size
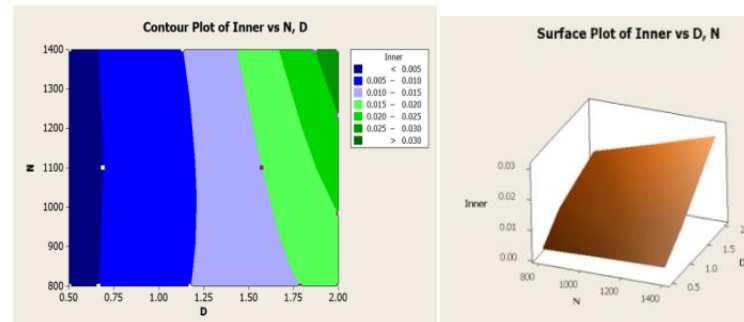

Fig 10 Contour plot and surface plot for defect on inner race considering speed and defect size

From main effect plot are shown in Figure 8 , that with defect size it will shows large variation in linear manner but for increasing in speed we cannot seen much steepest slope as compared with outer race and ball defect. Also for Increasing in Load we can get the slope decreasing in linear manner. The same results are seen in the contour plots Figure 9and Figure 10 and surface plots in these plots. It will go near to experimental values $[3,9]$.

\section{CONCLUSIONS}

In this present work, extensive experimentation is done in which experimental test setup is established and different defects are introduced on different bearings for performing laboratory tests. For each defect, the defect frequencies are first computed for various loads steps and speeds of the shaft. The occurrence of peak amplitudes of vibration at multiples of varying compliance frequencies, are observed along with the interactive effects of various parameters. The RSM is performed and a linear relation between amplitude of vibrations and various other parameters is developed. The expression developed by RSM is validated with different experiments. This study concluded with some interesting results like amplitudes are increasing with defect size and speed but decreases with increasing load. Finally, the values of vibration amplitudes measured in experiments are compared with the values predicted by RSM with good equivalence between them.

\section{NOMENCLATURE}

\begin{tabular}{|l|l|}
\hline $\mathrm{T}_{f}$ & $=$ Theoretical defect frequency \\
\hline $\mathrm{E}_{f}$ & $=$ Experimental defect frequency \\
\hline $\mathrm{Hz}$ & $=$ Hertz \\
\hline $\mathrm{O}_{f}$ & $=$ Outer race defect frequency \\
\hline $\mathrm{R}_{f}$ & $=$ Roller defect frequency \\
\hline $\mathrm{O}_{\mathrm{d}}$ & $=$ Outer race defect \\
\hline $\mathrm{R}_{\mathrm{d}}$ & $=$ Roller defect \\
\hline FFT & $=$ Fast Fourier Transform \\
\hline DOE & $=$ Design of Experiments \\
\hline RSM & $=$ Response Surface Method \\
\hline
\end{tabular}

\section{REFERENCES}

[1] N. Tandon, A. Choudhury., 1999, A review of vibration and acoustic measurement methods for the detection of defects in rolling element bearings, Tribology International, Vol. 32, pp. 469-480.

[2] Jose Mathew, M. S. Patil, P.K. Rajendrakumar, Sandeep Desai., 2010, A theoretical model to predict the effect of localized defect on vibrations associated with ball bearing, International Journal of Mechanical Sciences, Vol. 52 , pp. 1193-1201.

[3] M. S. Patil, Jose Mathew, P.K. Rajendrakumar, Sumit Karade., 2010, Experimental Studies Using Response Surface Methodology for Condition Monitoring of Ball Bearings, Journal of Tribology, Vol. 132, 044505-1-044505-7,ASME.

[4] Zeki Kiral, Hira Karagulle., 2006, Vibration analysis of rolling element bearings with various defects under the action of an unbalanced force, Mechanical Systems and Signal Processing, Vol. 20, pp. 19671991. 
[5] A. Choudhury, N. Tandon., 2006, A theoretical model has been developed to obtain the vibration response due to a localized defect in various bearing elements in a rotor-bearing system under radial load conditions, Journal of Tribology, Vol. 128, pp. 252261.

[6] Gallina A, Martowicz, A, Uhl T., An Application of Response Surface Methodology in the Field of Dynamic Analysis of Mechanical Structures Considering Uncertain Parameters, ISMA 2006 Conference, Leuven, Belgium.

[7] Jun M., 1995, Detection of Localised Defects in Rolling Element Bearings via Composite Hypothesis Test, Mechanical Systems and Signal Processing, Vol. 9(1), pp 63-75.

[8] Box, G. E. P., and Behnken, D. W., 1960, Some New Three Level Designs for the Study of Quantitative Variables, Technometrics, Edition 2, pp. 455-475.

[9] Raymond H. Myers, Douglas C. Montgomery, Christine M. Anderson-cook, 2009, Response Surface Methodology Process And Product Optimization Using Designed Experiments, A John Wiley and Sons Inc. Publication, 3rd Edition, pp 19- 27

[10] Roller Bearing Catalogue, October 2012, SKF Group. 